\title{
TRES DISEÑOS DE MEDALLAS DEL PINTOR PORTUGUÉS VIEIRA LUSITANO EN LA COLECCIÓN DEL MUSEO DEL PRADO*
}

\author{
Pilar Diez del Corral Corredoira ${ }^{1}$ \\ Universidad Nacional de Educación a Distancia (UNED)
}

\begin{abstract}
En la colección de dibujos dieciochescos del Museo Nacional del Prado se conservan tres sanguinas de reducidas dimensiones que representan diseños del anverso de tres medallas conmemorativas. Las tres piezas fueron catalogadas en su día como anónimas y datadas de forma general en siglo XVIII. El objetivo del presente artículo es establecer la autoría de estos folios a través de su estudio y comparación con otras piezas conservadas en colecciones portuguesas, al tiempo que se profundiza en la relación de su autor con su formación temprana dibujando glíptica romana. Asimismo, se propondrá una interpretación y datación de las sanguinas en el contexto de la producción como dibujante y grabador de su artífice, que no es otro que Francisco de Matos (1699-1783), más conocido como Vieira Lusitano.
\end{abstract}

Palabras clave: Museo del Prado; dibujo; Settecento; Portugal; Vieira Lusitano; glíptica romana; Antoine Mengin.

\section{THREE DRAWINGS FOR MEDALS BY THE PORTUGUESE PAINTER VIEIRA LUSITANO} AT THE PRADO MUSEUM

The Prado Museum holds three small red chalk drawings that depict the obverse of three commemorative medals. None of them has a known author, and they are kept as part of the Prado's eighteenth-century drawing collection. This article aims to establish the authorship of these drawings through analysis and comparison with other works in Portuguese museums, as well as through an investigatinon of the artist's early training in the drawing of Roman stone carvings. Further, these drawings are studied and dated in the context of the artistic production of their author as both draughtsman and engraver: he was none other than Francisco de Matos (1699-1783), better known as Vieira Lusitano.

Key words: Prado Museum; Drawing; Settecento; Portugal; Vieira Lusitano; Roman stone carvings; Antoine Mengin.

Cómo citar este artículo / Citation: Diez del Corral Corredoira, Pilar (2021) "Tres diseños de medallas del pintor portugués Vieira Lusitano en la colección del Museo del Prado". En: Archivo Español de Arte, vol. 94, núm. 376, Madrid, pp. 351-364. https://doi.org/10.3989/aearte.2021.20

Entre el rico acervo de dibujos dieciochescos del museo del Prado se conservan tres sanguinas de reducidas dimensiones que reproducen los diseños del anverso de tres medallas conmemorativas. Hasta la fecha las tres obras han sido catalogadas como anónimas y datadas de forma genérica en siglo XVIII. En este artículo se pretende establecer certezas en torno a la autoría de estos folios

\footnotetext{
* Este artículo forma parte de los resultados del proyecto de investigación Ramón y Cajal (2017-22131) titulado "Academias artísticas, diplomacia e identidad de España y Portugal en la Roma de la primera mitad del siglo XVIII" financiado por el Ministerio de Ciencia e Innovación.

1 diezdelcorralcorredoira@geo.uned.es / ORCID iD: https://orcid.org/0000-0001-6728-5205
} 
a través de su estudio y comparación con otras obras conservadas en colecciones portuguesas. Asimismo, se propondrá una interpretación y datación las sanguinas en el contexto de la producción del que indudablemente fue su autor, Francisco Vieira de Matos (1699-1783), más conocido como Vieira Lusitano. Con el objetivo de entender el sentido de estas tres sanguinas se profundizará en la carrera como dibujante y grabador de Vieira, que es con certeza el pintor portugués más importante del siglo XVIII y uno de los responsables de la introducción del gusto romano en la Lisboa de Juan V (1689-1750).

Las tres sanguinas proceden del legado de Pedro Fernández Durán y Bernaldo de Quirós $(1931)^{2}$ aspecto que dificulta la obtención de más datos sobre su procedencia. Según Pérez Sánchez ${ }^{3}$ una parte de las obras se adquirió en la venta Lefort, ${ }^{4}$ mientras que el resto de las piezas parecen proceder de las colecciones de Ceán Bermúdez (1749-1829) y Valentín Carderera (1796-1880). No resulta crucial para nuestro estudio conocer cómo llegaron a España, dado que es sabido que la obra gráfica de Vieira Lusitano circuló por toda Europa en vida del pintor, por lo que no es especialmente significativa su presencia en el Prado. ${ }^{5}$ Esta dispersión de su obra hace que todavía hoy sea necesario conducir un estudio profundo de su presencia en las colecciones europeas. En muchas ocasiones sus dibujos van aflorando cada cierto tiempo bajo atribuciones erróneas, normalmente del círculo de Carlo Maratta (1625-1713) o simplemente como piezas anónimas. Así aparecen las tres sanguinas que nos ocupan que, por sus características formales, es indiscutible que pertenecen al mismo artífice. Poseen además medidas similares, a pesar de que dos de ellas fueron adaptadas a un marco cuadrangular, y comparten el mismo papel amarillento verjurado.

Técnicamente estas sanguinas son contrapruebas de dibujos originales, algo que se evidencia por la falta de trazo claro, el aspecto difuminado y los contornos borrosos. La contraprueba es una técnica muy habitual para obtener copias exactas y se realiza ejerciendo presión sobre el dibujo original, sobre el que previamente se coloca un folio humedecido, produciéndose así una transferencia. Cuantas más veces se realice esta operación más difuminado es el resultado final. Esta práctica es muy común entre artistas ya que les permitía conservar copias de sus creaciones, que podrían servir para su uso personal, como libros de modelos o memorias, o como objetos de intercambio con otros artistas o amigos. ${ }^{6}$

Estos tres folios no son únicos en su temática, pero probablemente sean los que muestren un mejor estado de conservación, lo que hace pensar que pudieron ser las primeras contrapruebas del dibujo original, cuya ubicación, en caso de que se conserven, se desconoce. La medalla Felicitas duplex tiene su compañera en el Museu Nacional de Arte Antiga (Lisboa; inv. 2354); donde también se conserva Illaesa contrivii (inv. 2354), ambas son contrapruebas pero de calidad inferior a las del Prado, mientras que de la de Mercedes virtutum se conoce un dibujo preparatorio en el Museu de Évora (ME 674/2).

Desde el punto de vista técnico no hay duda alguna sobre su atribución a Vieira Lusitano, ya que aunque no se conociesen las contrapruebas en colecciones portuguesas, las sanguinas españolas muestran los rasgos más reconocibles de su dibujo, es decir, contornos suaves, composiciones espacialmente sencillas y cargadas de elementos alegóricos y/o emblemáticos, figuras ligeras, rostros redondeados y amables y constantes alusiones a modelos seicentescos, principalmente a Carlo Maratta y Andrea Sacchi (1599-1661).

\footnotetext{
2 El legado de Durán depara otras sorpresas ya que se conserva al menos otro folio de Vieira también como anónimo. Se ha interpretado como el tránsito de un santo jesuita (inv. D001403), pero en realidad se trata de un boceto para el éxtasis de San Juan de Dios, una obra hasta la fecha desconocida y sin atribuir a Vieira. Sobre este asunto véase mi artículo en vías de publicación: "An unknown project by Vieira Lusitano for King John V of Portugal. The ecstasy of Saint John of God for the church of Menino Deus".

3 Pérez Sánchez, 1977: 6-7.

${ }^{4}$ Lefort, 1869.

5 Turner, 2007. Arruda, 2000; 1999.

${ }^{6}$ Seigneur, 2004.
} 


\section{La formación romana de Vieira y la glíptica}

A pesar de que Vieira es una figura de singular importancia en el panorama portugués del siglo XVIII y con un notable éxito como dibujante, atestiguado por sus contemporáneos, poco se sabe sobre su rica producción gráfica y nada sobre su interés por el diseño de medallas. ${ }^{7}$ Apenas tenemos datos sobre su labor como grabador, con la que se hizo un nombre durante su estancia en Roma entre 1721 y 1728 y que le permitió sobrevivir en una ciudad en la que la competencia artística era tal que a duras penas un extranjero podía hacerse un hueco en el mercado. Sin embargo, Vieira tuvo la suficiente visión como para redirigir su formación hacia el mundo del dibujo y el grabado llegando a recibir notables encargos en Roma antes de regresar definitivamente a Lisboa en $1728 .{ }^{8}$ No en vano el portugués ya estaba familiarizado con el ambiente artístico romano, ya que en su adolescencia pudo formarse en el taller de Francesco Trevisani (1656-1746) y en el de Benedetto Luti (1666-1724), gracias al apoyo que recibió del marqués de Fontes, D. Rodrigo de Sá e Meneses (1676-1733), el embajador extraordinario de Juan V en Roma entre 1712 y $1718 .^{9}$

Vieira residió en el palacio del embajador como parte de su comitiva el tiempo que duró su misión, así como un año extra que consiguió "negociar" con el marqués para continuar con su formación artística. El embajador, hombre culto y coleccionista de arte, así como aficionado a la arquitectura, ya había visto las cualidades del joven cuando decidió llevárselo con él con apenas 13 años, pero la estancia en Roma le había confirmado sus sospechas, de forma que, cuando el muchacho reveló su valía ganando el tercer premio de Prima Classe del Concurso clementino de $1716,{ }^{10}$ el marqués no vio inconveniente en concederle un año más en la ciudad pontificia.

El embajador, además de sus deberes políticos, se movía dentro de un círculo de eruditos y coleccionistas. Entre sus intereses destacan las bellas artes, algo que se evidencia ya en sus primeras visitas oficiales cuando se interesó por conocer de primera mano la institución artística extranjera más sobresaliente del momento, la Academia de Francia (fundada en 1666), ${ }^{11}$ que visitó en compañía de otro gran personaje de la vida cultural lusa en Roma, el enviado especial de Juan V, Don Andrea de Melo e Castro, Conde das Galveias (1668-1753). ${ }^{12}$

En ese ambiente el joven Vieira floreció y debió de dar sus primeros pasos en el mundo de la medallística, ya que el marqués, como muchos de sus contemporáneos, tenía debilidad por el coleccionismo de gemas y monedas. Después de su temprana muerte en 1733 y a través de su inventario de bienes se pueden conocer algunos detalles de su colección, y aventurar qué parte se formó en Roma. Destaca la presencia de escultura antigua, sobre todo de bustos de emperadores, que constituían un elemento habitual en la época para componer galerías de personajes históricos. En la colección aparece algún elemento arquitectónico, como fragmentos de columnas, y se llega a mencionar incluso un grupo escultórico, aunque actualmente nada se sabe sobre su fortuna. Cabe destacar, sin embargo, que es la pasión por las gemas lo que parece caracterizar la colección que legó a sus descendientes, a tenor de la descripción del inventario que en otros aspectos resulta lacónico: "Os camaseos pasão de 150 em que entrão alguns de notavel grandeza e rarirade sendo a

\footnotetext{
${ }^{7}$ Arruda, 2015.

${ }^{8}$ Diez del Corral, 2018

${ }^{9}$ Diez del Corral / Fernandes, 2020.

${ }^{10}$ Archivio Storico dell'Accademia di San Luca, 1. 46a , fol. 210, 2 junio de 1716.

${ }^{11}$ Con probabilidad el marqués de Fontes fue el impulsor de la apertura de la Academia de Portugal en Roma, empresa que no pudo completar durante su misión, pero que abriría sus puertas en el Palacio Magnani en torno al 1722 y cuya vida efímera no dejó de despertar envidias y habladurías. Para la academia de Portugal véase: Diez del Corral, 2019. Para la atención negativa recibida por la institución véase: Diez del Corral, $2018 \mathrm{~b}$.

12 Sobre la figura de André de Melo como mecenas musical véase Fernandes (2021) y sobre su misión y sus problemas de ceremonial mi artículo: "The first diplomatic headquarters of King John V in Rome: the Buratti palace and the constitution of the Melo e Castro household" (en revisión).
} 


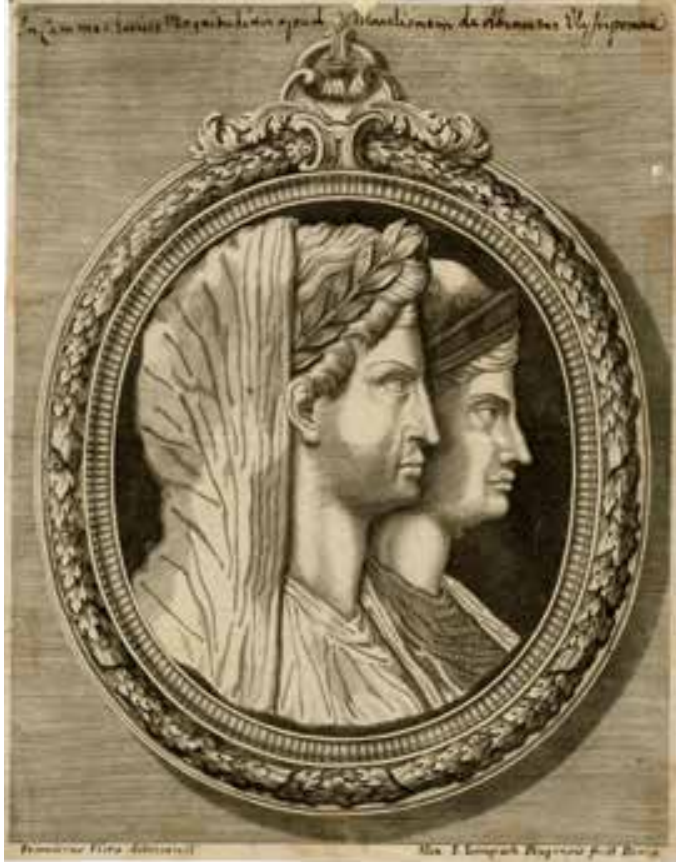

Fig. 1. Vieira Lusitano y Maximiliam Limpach, Gema de Augusto y Marcelo, Museo Británico (Fot. The Trustees of the British Museum).

mayor parte delles guarnecidos de prata dourada e alguns com diamantes e outra com pedras preciosas". 13

Es evidente que ahí debían de mezclarse obra antigua con moderna e incluso falsificaciones, en la tónica de los gabinetes del momento, al igual que sucedía con las monedas y medallas de las que llegó a tener un ingente número "de varios Reinos e Emperadores antigos e modernos". ${ }^{14}$ Una buena parte de esta colección debió de adquirirse en el ambiente romano, cuyo mercado estaba altamente especializado, y con ella regresaría a Lisboa en donde continuaría con su labor de construir un verdadero gabinete numismático. ${ }^{15}$

Entre los eruditos que estaban en contacto directo con el marqués destacaba Francesco Bianchini (1662-1729), superintendente de antigüedades de Clemente XI (1700-1721) desde 1703, y por cuyas manos pasaban todos los hallazgos de las excavaciones en curso en la ciudad. Bianchini, cuyo papel en la corte de Lisboa es conocido, fue uno de los intermediarios más influyentes del marqués y aún después de regresar a Lisboa mantuvo vivo un intenso contacto epistolar debido a encargos reales. ${ }^{16}$

La carencia de datos sobre la colección del marqués y su gestación impide hacer una reconstrucción y una valoración objetiva de la misma. Sin embargo, se conservan al menos dos grabados que podrían arrojar luz sobre parte de las piezas que formaron parte de su gabinete, en concreto sobre las gemas y camafeos. Además, sendos grabados, a mi juicio, podrían atestiguar la existencia de un fascinante y desconocido proyecto editorial de envergadura para dar a conocer las mejores piezas de la gliptoteca del embajador. El primer grabado es un aguafuerte que ilustra una gema con Augusto y Marcelo [fig. 1]. ${ }^{17}$ La historiografía no ha prestado la debida atención a la pieza más allá de atribuirla como obra de juventud de Vieira en su primera estancia romana sin ningún estudio específico, a pesar del interés de la misma para entender los primeros años de Vieira y su formación. ${ }^{18} \mathrm{El}$ grabado aparece posteriormente publicado como parte de las ilustraciones del libro del anticuario y especialista Francesco Ficoroni (1664-17747) Le Vestigia e rarità di Roma antica ricercate, e spiegate (Roma, 1744), aunque se conservan copias en folios sueltos en diferentes colecciones (por ejemplo: Museo Británico, inv. 1897,0113.110).

Ficoroni era otro personaje de peso en el mercado romano de la primera mitad del siglo XVIII y es muy plausible que el embajador portugués lo hubiese conocido personalmente. El grabado aparece en el libro I (cp. XXI, p. 144) y reproduce una gema de ágata con las efigies de Augusto y Marcelo, que era considerada una rareza por su tamaño y sus colores. Precisamente una observa-

${ }^{13}$ Archivo Nacional da Torre do Tombo (ANTT), Casa Abrantes, n. ${ }^{\circ}$ 161, doc. 3180: citado por Delaforce, 2002 : 416 , n. 141 y 143 .

${ }^{14} \mathrm{La}$ información relativa a su colección de monedas y medallas, entre las que había una importante presencia de monedas portuguesas proviene del inventario de D. Joaquim Francisco, hijo del marqués de Fontes en 1756, ANTT, Casa da Suplicação, Juizos Diversos, maço 424, Caixa 3222, citado por Delaforce, 2002: 416 n. 146.

15 Diez del Corral, 2021: 49-50.

16 Delaforce, 2019: 211 y siguientes.

${ }^{17}$ Vieira Lusitano y Maximiliam Limpach, Gema de Augusto y Marcelo, Museo Británico, inv. 1897,0113.110.

${ }^{18}$ Por ejemplo, Delaforce, 2002: 152. 

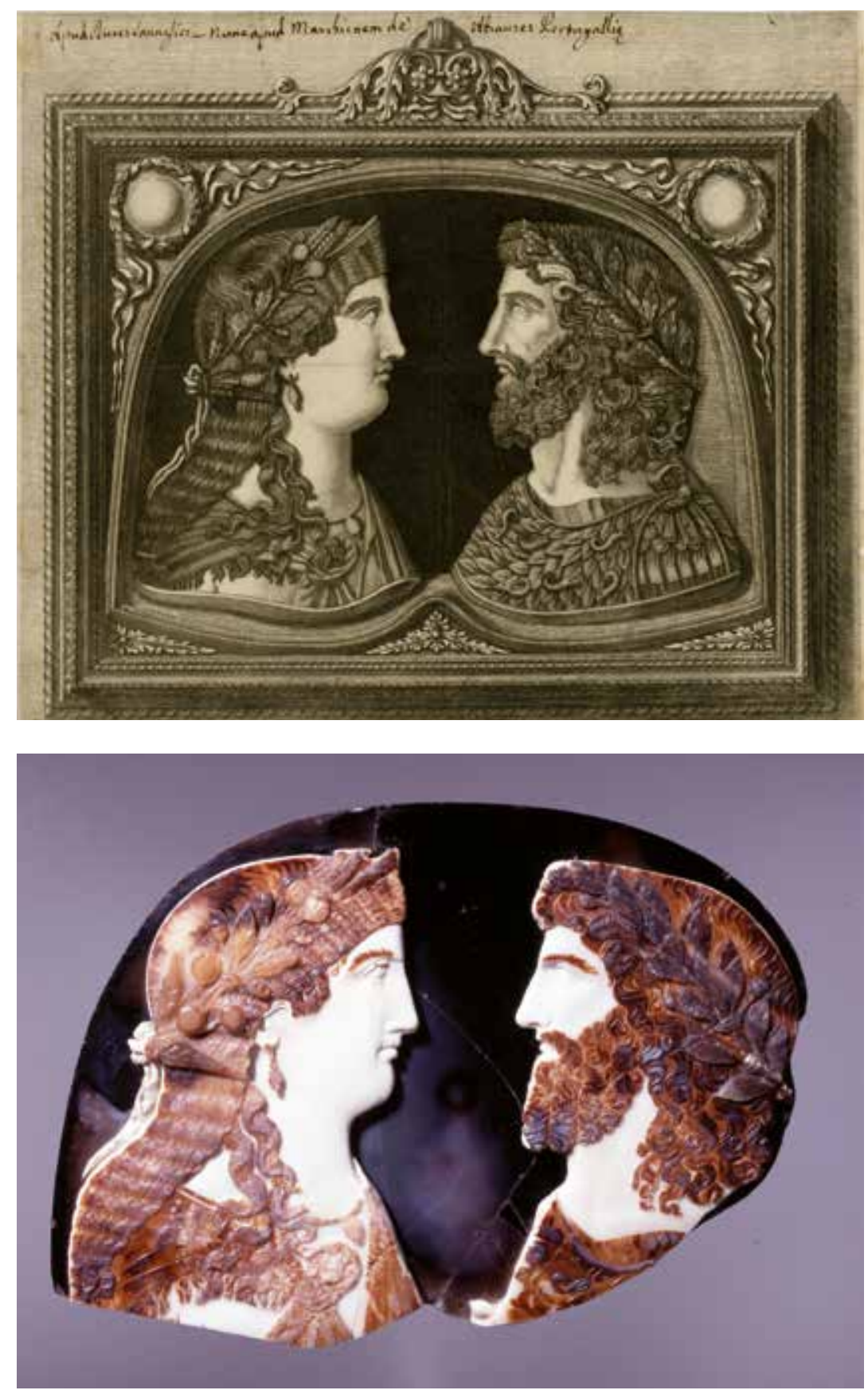

Fig. 2. Vieira Lusitano y Maximiliam Limpach, Gema de Démeter y Zeus Amón, Museo Británico (Fot. The Trustees of the British Museum).
Fig. 3. Camafeo romano de Juno / Isis y Zeus Amón, Museo Británico (Fot. The Trustees of the British Museum).

ción detenida de sus características formales lleva a sospechar que se trataba de una falsificación moderna, aspecto hasta ahora que no ha sido señalado por los estudiosos y que revela una de las prácticas habituales en el mercado de antigüedades del momento, es decir, la falsificación de piezas que se vendían como llegadas directamente de una excavación y que compraban los numerosos grand-turistas que poblaban temporalmente la ciudad pontificia. Vieira realizó el dibujo original, que no se conserva o conoce, y el checo Maximiliam Limpach (activo entre 1700 y 1730 en Roma) lo grabó.

El segundo grabado de este posible proyecto editorial es fruto de otra colaboración entre Limpach y Vieira, pero nunca fue publicado en la obra de Ficoroni. Se trata de otro aguafuerte con 
claras similitudes formales y hoy conservado en el Museo Británico (inv. 1897,0113.109), que reproduce el montaje sobre marco moderno de dos camafeos romanos enfrentados también de la colección del embajador [fig. 2]. En este caso se presentan dos efigies de Juno / Isis y de Zeus Amón. Esta reproducción muestra elementos propios de una pieza antigua, como los característicos ojos abultados de las divinidades, que nos ayuda a datarlo en la dinastía Julio-Claudia, probablemente en época de Calígula, por lo que se concluye que se correspondería con un original romano. ${ }^{19} \mathrm{De}$ hecho la pieza original se encuentra hoy en el Reino Unido y casualmente en la misma colección del Museo Británico (inv. 3619) aunque ya no presenta el marco que tenía en época del marqués y que, sin duda, fue una adición para hacerla más atractiva para la exposición en un gabinete [fig. $3] .^{20}$

Ante ambos grabados, con obvias semejanzas técnicas y estilísticas, es posible especular que nos hallemos ante los únicos ejemplos conservados de un proyecto más ambicioso e inconcluso sobre las mejores piezas de la colección del marqués. Una iniciativa de estas características no desentonaría con la construcción de la imagen del marqués de Fontes en Roma y con las prácticas habituales de coleccionistas del mismo rango. El joven Vieira sería el artífice y eso encaja con parte de sus tareas como miembro del cortejo del embajador, ya que no solo viajaba para adquirir una formación en la "academia de Europa", sino que entre sus deberes se contaban una serie de proyectos a cargo de su mecenas y del propio rey. En su autobiografía llega incluso a lamentarse del poco tiempo libre que tiene para proseguir con sus estudios debido a la carga de trabajo extra que le encargaba su mentor. Menciona ${ }^{21}$ con frustración cómo los pormenorizados dibujos que realizó de los carruajes de la entrada triunfal del embajador fueron olvidados, a pesar de la intención original de emular la obra de De Bellevat, Relation du Voyage de Monseigneur André de Mello e Castro à la Cour de Rome (Paris: Anisson, 1709), en la que se reproducía, entre otras cosas, la serie de carruajes de la puesta en público del enviado especial en 1709. Si se tiene presente que la inversión en propaganda, entendida en un sentido lato, e imagen de la corona portuguesa en Roma llegó a su culmen durante los primeros veinte años del reinado, ${ }^{22}$ durante los cuales hubo un especial interés en la impresión de todo tipo de obras, sería plausible considerar un proyecto sobre el gabinete de Fontes entre las iniciativas a mayor gloria de Portugal. Resulta, por tanto, verosímil que ambos grabados de Limpach sobre dibujos de Vieira sean los únicos vestigios conocidos hasta la fecha de una publicación que alabase el gusto del marqués de Fontes y por ende de Portugal. En este punto de la investigación no resulta posible aventurar nada más allá de las conjeturas construidas sobre la base de estos dos grabados, ya que se desconoce si se llegaron a realizar más dibujos o si estos dos folios son el único testimonio de esa hipotética publicación.

Ambos grabados conservan, además, indicios que recuerdan su pasado "portugués" en las versiones que custodia el museo británico. En el grabado de Juno/Isis y Zeus Amón [fig. 2] aparece en la parte superior una anotación caligráfica que se puede datar en el mismo siglo XVIII. En ella se da cuenta del primer propietario de la pieza y del actual - que podría transcribirse como duque Jannies - : "Apud Duces Jannessies [?] - Nunc apud Marchionem de' Abiauses [Abrantes] Portugallie". El folio de la gema de Augusto y Marcelo [fig. 1] que se conserva en el Museo Británico —no así la copia en el libro de Ficoroni- presenta el mismo tipo de anotación: "In cammeo eius Magnitudinis apud Marchionem de' Abiauses Ulyssiponae". Resulta muy arriesgado aventurar en qué momento se hizo esta anotación, pero la mención al embajador como marqués de Abrantes, título que solo obtuvo después de su regreso a Lisboa en 1718, ayuda a datar la inscripción al menos a partir de esa fecha. Estos grabados debieron, por tanto, circular en Roma después del regreso del embajador, por lo que es posible que se imprimiesen nuevas copias durante el período de actividad de Limpach hasta el 1730, e incluso más tarde, si atendemos a la fecha de publicación de la obra de Ficoroni en 1744. Éste debió de seleccionar la gema de Augusto y Marcelo por su

\footnotetext{
19 Agradezco al Prof. Dr. David Ojeda Nogales su inestimable ayuda a la hora de datar y estudiar ambas piezas.

${ }^{20}$ Camafeo en sardónice en tres capas, 15 x $22 \mathrm{~cm}$. Megow, 1987: 276-277.

${ }^{21}$ Vieira Lusitano, 1780: 204-208.

${ }^{22}$ Ribeiro, 2019.
} 
rareza y reutilizar el grabado de Limpach, ya que se trata de la única ilustración firmada en toda la obra. La reutilización de placas es un fenómeno que se retrotrae a la Edad Media y en este caso la pieza debía de ser lo suficientemente famosa como para que Ficoroni la recuperase años después de que su dueño dejase Roma.

A modo de recapitulación se puede establecer con cierta certeza que existieron al menos "dos versiones" de los aguafuertes que podamos conocer su uso. La primera, sería aquella sin inscripción, que podría responder a una publicación inconclusa del gabinete de gemas y probablemente fuese un encargo personal del marqués, aunque poco podemos saber sobre el mismo. Cuando el marqués abandonó Roma, los grabados circularon durante un tiempo indeterminado y Ficoroni seleccionó el de la gema de Agusto y Marcelo para su publicación de 1744, probablemente por su rareza, mientras que sendas copias de las dos gemas pasaron a formar parte de un hipotético álbum de algún coleccionista que decidió anotar a mano la procedencia de las dos piezas. En este sentido, cuando el Museo Británico compró los folios, se registra que debieron de formar parte de un álbum que se desmontó para su venta. Muchos de los folios de ese álbum, adquiridos a su vez por el museo, tienen el nombre de Johann Adam von Greis y recopilaban reproducciones raras del siglo XVI y siglo XVII italiano. No se conoce nada sobre la actividad coleccionista de von Greis, pero resulta verosímil que las anotaciones a mano fuesen obra suya o de su marchante romano.

Por último, estos grabados dieron la oportunidad a Vieira de familiarizarse con la técnica del aguafuerte, que llegaría a dominar en poco tiempo, y es posible que ya entonces aprendiese a realizar las placas, porque la otra obra conocida de este período de juventud y vinculada al coleccionismo del marqués es una medalla conmemorativa de la misión diplomática en Roma. ${ }^{23}$ De la medalla, que probablemente no llegó a fundirse, no se conservan tampoco los dibujos preparatorios, pero la historiografía se la atribuye como uno de los primeros pasos de Vieira en el mundo de la estampa y da testimonio del grado de maestría que demostraba con apenas 17 años cumplidos. En esta medalla se ven ya algunas características del arte del portugués, que irá puliendo con los años, pero, sobre todo, nos permite ubicar con cierta seguridad la producción de los diseños conservados en el Prado, como mínimo, con una fecha post quem, desde finales de la segunda década del siglo XVIII.

\section{Las sanguinas del Museo del Prado}

Desde el punto de vista iconográfico los tres folios madrileños presentan temas reconocibles y reconducibles en su mayoría a encargos documentados u obras similares que permitirían ubicarlos en el contexto de la larga carrera profesional de Vieira, pero sorprendentemente desde los primeros trabajos de catalogación numismática de principios del siglo XX no han despertado el interés esperable de los historiadores del arte. ${ }^{24}$

La medalla Felicitas dúplex [fig. 4] ${ }^{25}$ es la única que ha sido estudiada con profundidad vinculando su temática con los dobles esponsales hispano-portugueses de 1729 y de la que, como ya se señaló más arriba, se conserva otra contraprueba de peor calidad en el Museu Nacional de Arte Antiga (inv. 2354), así como un dibujo preparatorio en el Museu de Évora (ME 701). ${ }^{26}$ La sanguina del Prado, al igual que la de Lisboa y el dibujo de Évora, muestra solo el anverso de la medalla con sendas alegorías de las dos monarquías ibéricas, España y Portugal, como dos doncellas coronadas acompañadas por animales heráldicos. Aparecen abrazándose en un esquema habitual en biblias y salterios medievales y que vuelve a ponerse de moda en siglo XVI. Su

${ }^{23}$ Se conserva una copia en la Biblioteca Nacional de Portugal (BNP, Lisboa), E.75 PQ. : <http://purl.pt/22541> [08/01/2021].

${ }^{24}$ Lamas, 1907.

${ }_{25}$ Vieira Lusitano, Felicitas dúplex, h. 1729, sanguina, Museo Nacional del Prado (MNP), inv. D003519, medidas $173 \times 137 \mathrm{~mm}$.

${ }^{26}$ Diez del Corral, 2021. 


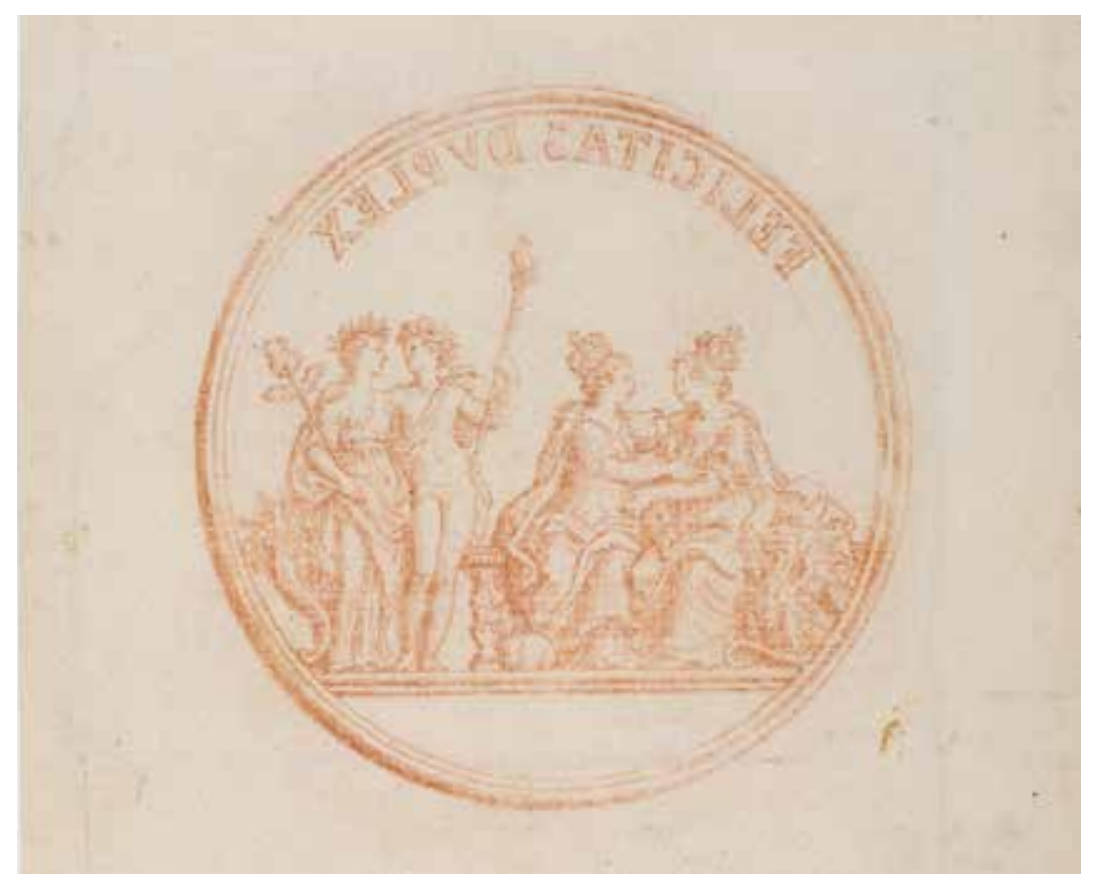

Fig. 4. Vieira Lusitano, Felicitas dúplex, h. 1729, Museo Nacional del Prado (Fot. Museo Nacional del Prado).

origen se encuentra en la interpretación más o menos literal del salmo 80, 10: "La misericordia y la verdad se han encontrado. La justicia y la paz se han besado". Esta temática, cuya versatilidad iconográfica es evidente, se suele asociar en Centroeuropa con imágenes del emperador Fernando II, los duques de Baviera o el emperador Rodolfo II, así como a la pax veneta. ${ }^{27}$ En este caso el esquema iconográfico se adapta con facilidad al momento de la unión de las dos coronas ibéricas.

Vieira posiblemente tome prestada la idea de François Harrewyn (1700-1764), un grabador de notable éxito, que pasó un tiempo en la corte lisboeta y realizó un grabado con tema similar. ${ }^{28} \mathrm{El}$ portugués lo adapta al formato en tondo y le añade dos divinidades para aclarar el sentido de la obra. Se trata de Himeneo y de la diosa romana Felicitas, ambos testigos muy apropiados para el ilustrar la prosperidad que se cierne sobre España y Portugal gracias a la unión de sus herederos en un doble matrimonio en 1729.

La medalla pretendía conmemorar, con toda certeza, los dobles esponsales conocidos como $a$ troca das princesas, que unieron al príncipe del Brasil con la princesa española y al príncipe de Asturias con la princesa portuguesa, es decir al futuro José I (1714-1777) con Mariana Victoria de Borbón (1718-1781) y al futuro Fernando VI (1713-1759) con María Bárbara de Braganza (17111758). ${ }^{29}$ No se conocen más datos sobre este proyecto, ni siquiera si se llegó a acuñar la medalla, pero en la producción de Vieira conocida hasta la fecha se conserva lo que se podría interpretar como un diseño alternativo para el mismo acontecimiento. Se trata de un dibujo preparatorio en sanguina del anverso de otra medalla conmemorativa de la que nada se sabe y que forma parte de la colección de dibujos del Museu de Évora (inv. 674/1). ${ }^{30}$ En el cuerpo de la medalla se representa un carro triunfal guiado por Himeneo, llevando a Minerva con los símbolos de la dinastía Braganza. La inscripción reza Concordiae Triumphum y en el exergo se hace referencia a la llegada de los esposos a Lisboa: "Adventus regum principum que ulisipono MDCCXXIX" ${ }^{31}$ El modelo de clara

\footnotetext{
27 Wohlfeil, 1991. Schreiner, 2001.

28 "Erunt duo in carne una", François Harrewyn, 1729, BNP, E. 237. A.: < http://purl.pt/6883>[08/01/2021].

29 Pereira, 2008. Pimentel, 2010.

$30<\mathrm{http} / / /$ www.matriznet.dgpc.pt/MatrizNet/Objectos/ObjectosConsultar.aspx?IdReg=18844>[ 28/08/2021].

$31<\mathrm{http}: / /$ www.matriznet.dgpc.pt/MatrizNet/Objectos/ObjectosConsultar.aspx?IdReg=18844>[26/02/2021].
} 


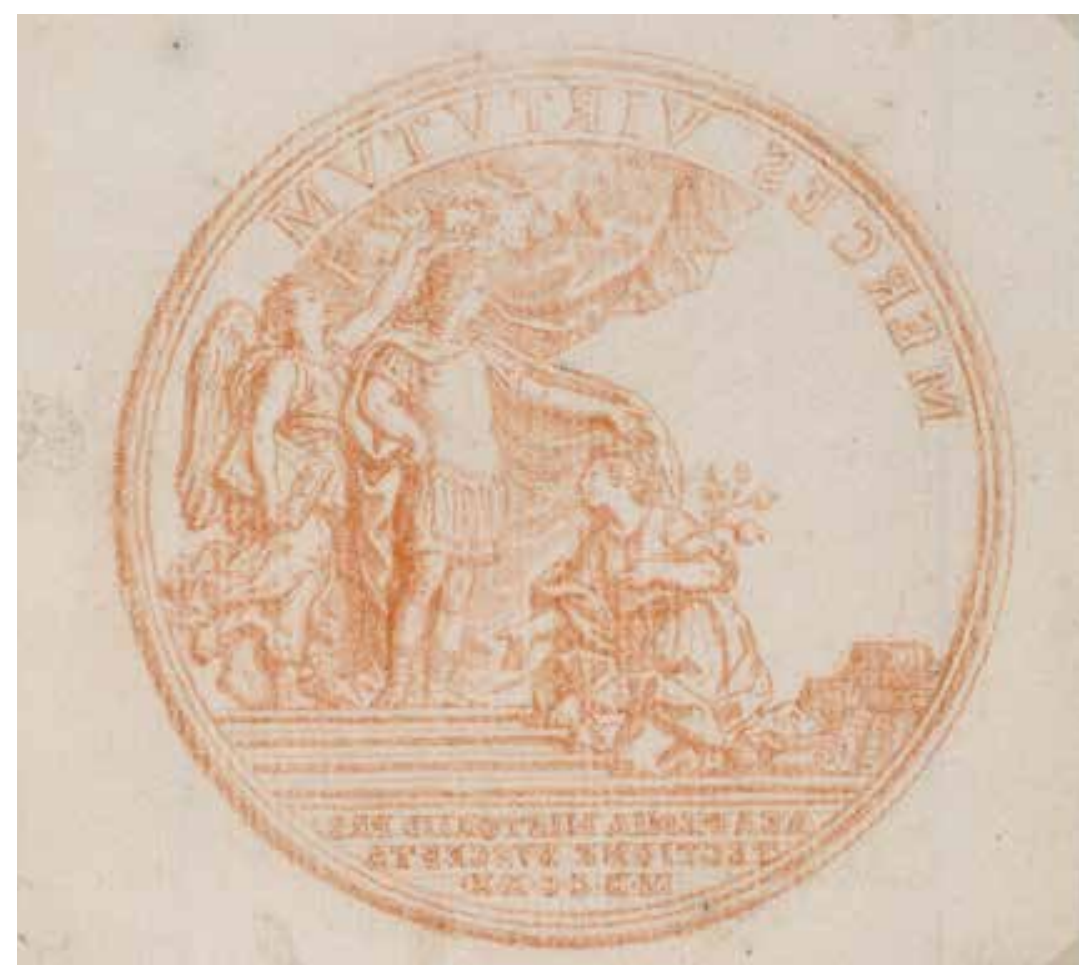

Fig. 5. Vieira Lusitano, Mercedes virtutum, h. 1720 , Museo Nacional del Prado (Fot. Museo Nacional del Prado).

raigambre clásica aparece también en medallas que aluden a la Paz de Westfalia (1648). ${ }^{32}$ Así las cosas, Vieira parece haber realizado al menos dos diseños para la conmemoración de los dobles matrimonios aunque no se conozca ninguna medalla con dicha temática.

El segundo dibujo del museo del Prado presenta también el anverso de otra medalla con la inscripción Mercedes virtutum [fig. 5] $]^{33}$ que nos muestra una versión acabada de un boceto preparatorio conservado en el Museu de Évora (inv. 654-2), ${ }^{34}$ pudiendo así analizar dos fases de la práctica artística de Vieira, que van del pensamiento inicial hasta la pieza final. Esta medalla, además del lema Mercedes virtutum, presenta tres figuras en el cuerpo y el exergo ocupado con la inscripción: "Academia historiae - Protectione Suscepta 1720", que permite reconocer e identificar con certeza su razón de ser. Se trata de un diseño para una medalla que celebra al protector de la Academia de la Historia Portuguesa fundada en 1720, que no es otro que el rey Juan V.

El boceto de Évora muestra una primera fase del diseño, de hecho, si se observa con atención se pueden ver pentimenti o correcciones en la inscripción del exergo. El dibujo fue publicado por Lamas en 1907, que ya entonces lo ligó a una medalla de la que se conservan algunos ejemplares ${ }^{35}$ que fue acuñada por Antoine Mengin (1693-1766) supuestamente sobre un diseño de Vieira. ${ }^{36}$ Tanto el boceto de Évora, que Lamas interpreta como un diseño descartado, como ahora la sanguina del Prado, vienen a confirmar la complejidad del proceso creativo de la pieza y la autoría del pintor portugués.

${ }^{32}$ Museo Arquelógico Nacional (Madrid), 2009/66/59: $<$ http://ceres.mcu.es/pages/Main?idt=51382\&inventary=200 9/66/59\&table=FMUS\&museum=MAN $>[26 / 02 / 2021]$.

33 Vieira Lusitano, Mercedes virtutum, h. 1720, sanguina, MNP, inv. D003520, medidas: 115 x $111 \mathrm{~mm}$.

$34<$ http://www.matriznet.dgpc.pt/MatrizNet/Objectos/ObjectosConsultar.aspx?IdReg=18845> [26/02/2021].

${ }^{35}$ Una versión en plata en el Museu da Casa da Moeda, 5 y 2968; y dos en oro en el Palácio Nacional da Ajuda (PNA, inv. 4878) y en el Palácio Nacional de Mafra (PNM, 7493). Agradezco a João Pedro Vieira, conservador del Museu do Dinheiro (Lisboa), estas referencias y el intercambio de ideas sobre la numismática en época joanina.

${ }^{36}$ Artista francés invitado por el rey a trabajar en Lisboa, primero como grabador y después como Grabador General de la Ceca Real (Pernas, 2018). 


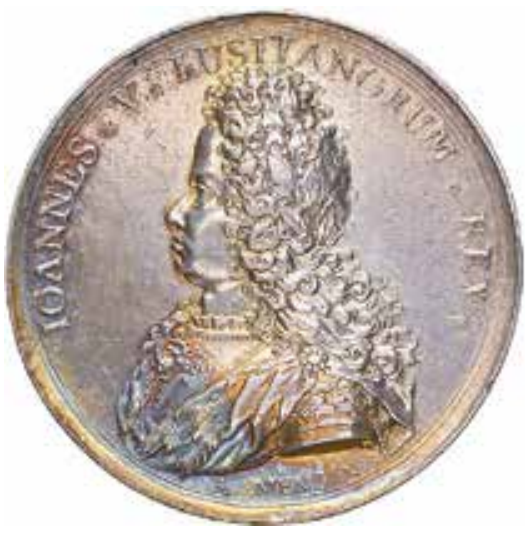

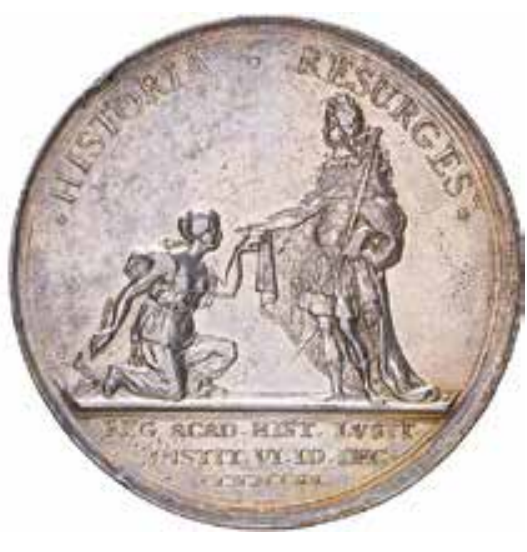

Fig. 6. Antoine Mengin sobre dibujo de Vieira Lusitano, Historia Resurges, h. 1721 (Fot. Numisma Leilões).

En las fechas en las que se acuñó, Vieira acababa de abandonar Lisboa para regresar a Roma, por lo que es perfectamente plausible que los diseños se correspondan con algún momento desde mediados del 1720 hasta su partida, que se produjo en una fecha desconocida en 1721.

Se conserva documentación suficiente, casi toda relativa a la historia de la Academia y correspondencia privada,$^{37}$ que permiten rastrear el origen del encargo y hasta identificar a su comitente, que no fue otro que el mismo D. Rodrigo de Sá, marqués de Fontes, entonces ya de Abrantes. No resulta por tanto extraño que siendo el protector de Vieira y conociendo su experiencia con la glíptica lo propusiese como artífice para el encargo, como tampoco el hecho que sugiriese el esquema iconográfico, que es un modelo all'antica que podía estar presente en su colección privada. Ya en el libro de la Historia da Academia real da Historia portuguesa $(1727$, p. 373) se menciona que la fuente de inspiración fue una moneda de época de Vespasiano, probablemente una consecuencia de la afición numismática del marqués. En esos años estaba D. Rodrigo de Sá ocupado en escribir una suerte de Historie métallique ${ }^{38}$ de Portugal, tomando como base su propia colección de monedas. La empresa se vio frustrada por la prematura muerte de su autor en 1733, pero fue parcialmente rescatada por Antonio Caetano de Sousa (1674-1759) en su Historia genealógica de la Casa Real Portuguesa (Lisboa, 1735, vol. IV), uno de los frutos más importantes de la labor intelectual de la Academia.

La composición que presenta la sanguina del Prado coloca a Juan V bajo un opulento cortinaje, homenaje al retrato barroco, pertrechado con coraza, sandalias y manto como un emperador romano, mientras una victoria alada lo corona de laureles. A los pies del podio sobre el que está el monarca, una alegoría de la Historia sostiene en su brazo izquierdo una rama de granadas y con la mano derecha presenta sus respetos al rey que, a su vez, la acoge magnánimo bajo su manto. A los pies de la Historia se amontonan pergaminos y libros, muestra de la producción intelectual de Occidente protegida ahora por el monarca luso. A pesar de que el diseño de Vieira recogía elementos fuertemente ligados a la imagen que Juan $\mathrm{V}$ pretendía crear de su reinado, es decir, vínculo directo con la Antigüedad e identificación con el Imperio y todo ello envuelto en una forma clásica y fácilmente legible, prevaleció un modelo menos profuso en detalles y, en cierta forma, más contemporáneo.

La medalla acuñada finalmente por Mengin [fig. 6] $]^{39}$ nos propone una imagen más sencilla. En el cuerpo, el rey y la Historia comparten el mismo plano y ella apenas lleva una pluma como atributo y un pergamino a sus pies. El cambio de atuendo del rey es de lo más elocuente: porta una coraza profusamente decorada y ha dejado atrás los laureles que cambia por un cetro, también

\footnotetext{
${ }^{37}$ Lamas, 1907.

${ }^{38}$ Este proyecto auspiciado por Luis XIV pretendía presentar una historia de la numismática y la medallística con un valor propagandístico del monarca francés. Louvois, protector de la Academia Real de Pintura y Escultura, fue el impulsor de la idea pero no llegaría a imprimirse hasta 1702, después de que Menestrier se adelantase con su Histoire du Roi Louis Le Grand, par les médailles a maypr gloria del rey galo en 1689. Mínguez, 2001, 74.

${ }^{39}$ Antoine Mengin sobre dibujo de Vieira Lusitano, Historia Resurges, h. 1721, oro, mercado de arte.
} 


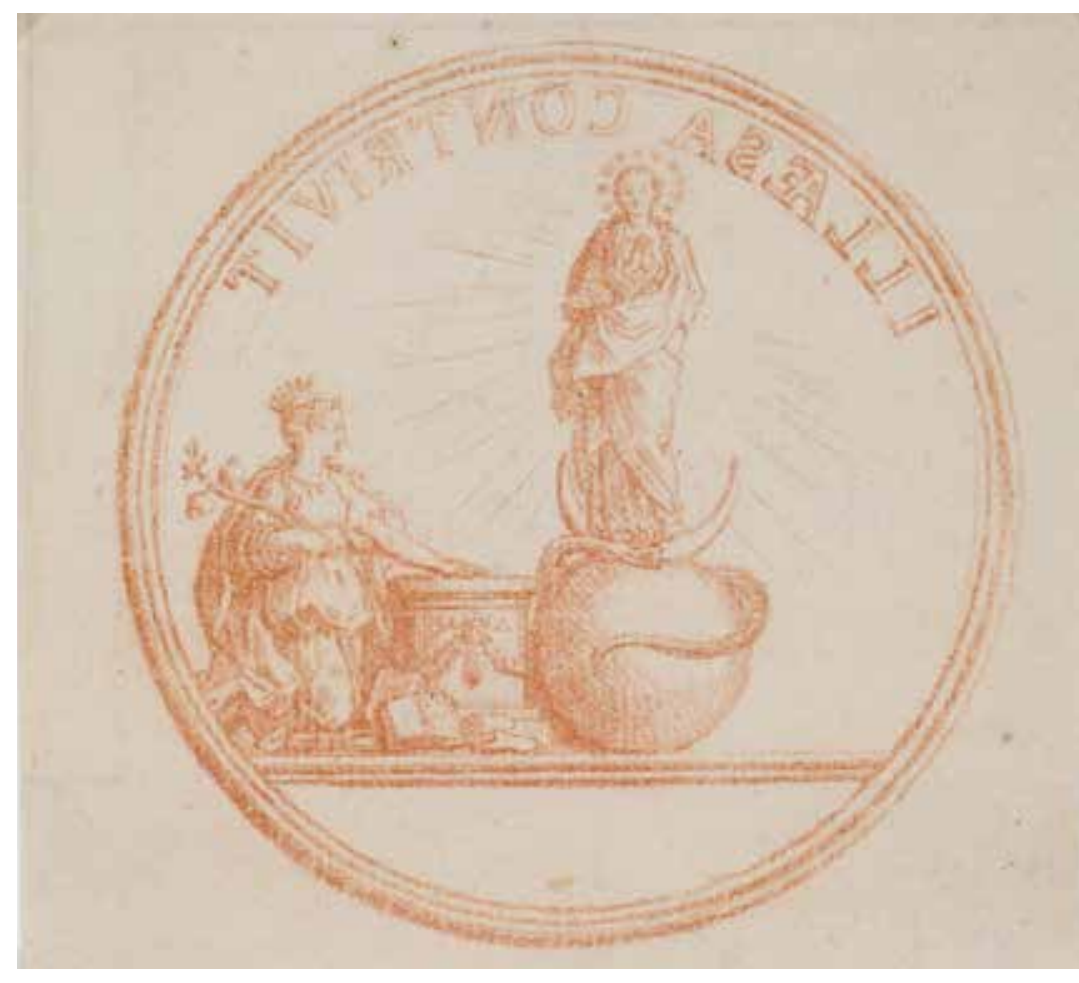

Fig. 7. Vieira Lusitano, Illaesa contrivit, h. 1720 , sanguina, Museo Nacional del Prado (Fot. Museo Nacional del Prado).

las sandalias, ahora calza botines, y, por último, el manto con fíbula, que cambia por una capa con pelliza de armiño. La transformación del emperador romano en un modelo de rey absoluto en armonía con los nuevos modelos franceses parece evidente y sin embargo, el esquema compositivo es indudablemente más clásico, ya que prácticamente es una transposición de las monedas Vespasianas que en su día se señalaron como fuente. ${ }^{40}$ La inscripción del exergo, "Regia Academia Historiae Lusitanae instituta VI Idus Decembris CICCICCCXX", revela la fecha de la fundación de la academia y el nuevo lema reza: Historia resurges, una clara alusión a su labor.

Esta medalla, y no el diseño previo que documenta la sanguina del museo del Prado, fue finalmente la que se entregó a Juan V como agradecimiento a su papel de protector el 22 de octubre de 1721, el día del aniversario del monarca, en una celebración en la que jugó un papel central el marqués de Abrantes, que entonces era el director de la institución.

La tercera y última sanguina, Illaesa contrivii [fig. 7], ${ }^{41}$ resulta ser la más enigmática al usar un tema muy común en el arte religioso: la Inmaculada Concepción. La Virgen aparece con su iconografía habitual: nimbada de estrellas, en actitud recogida sobre el orbe y la media luna y pisando la serpiente con uno de sus pies. En este caso el elemento clave para proponer una lectura del sentido de la medalla es la otra figura femenina que se encuentra arrodillada ante la visión celestial. La mujer posa su mano izquierda sobre un altar romano decorado con festones, mientras sostiene una rama con granadas en la mano derecha. A sus pies se apilan una serie de volúmenes. La presencia de las granadas y los libros, así como la cercanía con el modelo femenino de la medalla de conmemoración de la Academia llevan a deducir que se trata, de nuevo, de la personificación de la Historia. Esta vez no se inclina ante el rey, sino que parece ofrecer un "sacrificio" a la Virgen; la Historia clásica, representada ante un ara, se pone al servicio de un poder mayor, un poder trascendente, que se materializa en la epifanía divina. De no estar vacío el exergo de la medalla podría arrojar luz sobre el momento que conmemoraría la pieza y sobre su significado, ya que lo complejo de

${ }^{40}$ Lamas, 1907.

${ }^{41}$ Vieira Lusitano, Illaesa contrivit, h. 1720, sanguina, MNP, inv. D003521, medidas: 125 x $110 \mathrm{~mm}$. 
esta iconografía es la combinación de los motivos. Mi propuesta es que María podría entenderse como una transposición/personificación de Portugal, ya que la Inmaculada es la patrona y reina de la nación lusa de forma oficial desde el 1640. Existen suficientes afinidades formales entre esta medalla y las dos anteriores como para poder aventurar que Vieira debió de diseñarla en torno a las mismas fechas, y ello unido a la particular elección iconográfica permite especular una posible lectura de por qué y cuándo se le encargó al pintor.

En la medalla conmemorativa de Mengin de la Real Academia de la Historia se hace un homenaje a la figura de Juan $\mathrm{V}$ como patrono y protector de la institución $\mathrm{y}$, como se ha corroborado por la existencia de otros diseños de la medalla final, Vieira proporcionó al menos dos diseños para la acunación final. Asimismo, como se ha demostrado en otra sede, ${ }^{42}$ el dibujo de la medalla de Felicitas duplex es como mínimo uno de los dos diseños conocidos hasta la fecha que Vieira propuso para la celebración, por lo que se deduce que era una práctica habitual en la fase inicial de estos proyectos.

Mi propuesta es que esta medalla pudo constituir un diseño alternativo de la de Mercedes virtutum o Historia Resurges. Mi argumentación va más allá de identificar a la Virgen con Portugal, ya que existen otros elementos, que si bien sutiles no deberían de pasar desapercibidos al público erudito al que iba dirigida una pieza de estas características. En primer lugar, cabe mencionar que la fecha de la fundación de la Real Academia de la Historia Portuguesa no fue escogida al azar, sino que se hizo coincidir con el 8 de diciembre de 1720, es decir, el día de la Inmaculada Concepción. Además, la fecha en sí no solo era un sentido homenaje a la patrona y reina de Portugal, sino que la Academia tenía como fin recopilar y componer la gesta civil y eclesiástica de la historia de Portugal, en la que la figura de la Inmaculada tenía un peso esencial.

La relación de la Inmaculada Concepción con la historia nacional lusa se puede retrotraer al 1117, fecha de la expulsión de los musulmanes, momento en el que, según la tradición, se celebró una misa pontifical en su honor como acción de gracias. También aparece vinculada con el otro momento histórico clave para la identidad de Portugal, es decir, la batalla de Aljubarrota (1385), cuando las tropas lusas al mando del condestable Nuno Alvares Pereira (1360-1431) vencieron a la Corona de Castilla. El condestable mandó entonces construir el templo de Nuestra Señora del Castillo en Vila Viçosa bajo la advocación de la Inmaculada Concepción, refrendando así el creciente fervor popular. Durante la Unión Ibérica la devoción no flaqueó ya que era además patrona de España, pero será en la Restauração cuando la nueva dinastía Braganza retome a la Inmaculada como parte indisoluble de la identidad lusa. El nuevo rey Juan IV la proclamará reina y patrona de Portugal y de todos los territorios ultramarinos en una provisión del 25 de agosto de $1646 .{ }^{43}$ Asimismo instauró que en la universidad de Coimbra sus docentes, y más adelante también sus estudiantes, se comprometiesen a defender el dogma. Juan V reiterará ese compromiso de la universidad en 1717 mediante su respaldo para celebrar el día santo. ${ }^{44}$

La academia portuguesa en ciernes pretendía dar peso a la historia e identidad de Portugal y qué mejor forma de hacerlo que vincular su fundación a una fecha clave como el 8 de diciembre. Resulta, por tanto, plausible que la sanguina de Vieira en el Prado pretendiese representar a la Inmaculada como "Reina de Portugal", con la Historia inclinada ante ella, como una alegoría que homenajea a la nueva institución de patrocinio real. Esto permitiría ofrecer una datación aproximada en torno al 1720 o 1721, al igual que la sanguina de Mercedes virtutum y la medalla de Mengin, constituyendo todas ellas diferentes medios para transmitir el mismo mensaje.

En una primera aproximación podría resultar sorprendente que las tres sanguinas aquí analizadas presentasen solamente el anverso de las medallas y aunque no es descartable que se deba al azar, lo cierto es que entre todos los diseños de medallas de la producción de Vieira ninguno viene acompañado por reverso del mismo. La única excepción es el grabado de la medalla conmemorativa de la misión del marqués de Fontes en Roma, que se mencionó más arriba y se conserva en

42 Diez del Corral, 2021: 51.

${ }^{43}$ Será refrendado por Clemente X en la bula papal Eximia dilectissimi en 1671.

${ }^{44}$ Moreira das Neves, 1940. 
el en la Biblioteca Nacional de Portugal. ${ }^{45}$ La razón probablemente sea muy sencilla: las efigies reales en la numismática permanecían inmutables durante un período dilatado y es muy posible que para todas estas piezas se usase un diseño previo de Antoine Mengin, que llevaba desde 1720 a las órdenes de Juan $\mathrm{V}$ en la ceca real.

\section{Coda}

A los numerosos dibujos que se conservan en museos y colecciones portuguesas, que dan fe del interés que tuvo Vieira por la medallística y sus posibilidades para la alegoría, hay que sumar ahora estas tres sanguinas, que, a su vez, son testimonio claro de la enorme difusión que tuvo su obra fuera de las fronteras portuguesas. El vínculo con sus años formativos en Roma y sus primeros pasos en la glíptica, son aspectos que deben de ser estudiados con mayor profundidad y que probablemente puedan llevar a descubrimientos de nueva obra erróneamente atribuida a la escuela italiana del XVIII. Estos tres diseños de medallas conmemorativas permiten conocer de una forma más completa la labor de Vieira como creador de alegorías y difusor de modelos all'antica, aspecto de su profesión artística que, sin duda, aprendió y perfeccionó en Roma, pero cuyos frutos vinieron a redundar a mayor gloria de Portugal.

\section{BIBLIOGRAFÍA}

Arruda, Luisa (1999): Francisco Vieira Lusitano (1699-1783). Uma época de desenho, Dissertação, Facultade de Belas Artes, Universidade de Lisboa.

Arruda, Luisa (2000): Vieira Lusitano (1699-1783) o desenho, Catálogo da Exposição, Lisboa: Museu Nacional de Arte Antiga.

Arruda, Luisa (2015): "Francisco Vieira Lusitano desenhador e as artes decorativas do tardobarroco". En: Cavi, Sabina de (ed.): Dibujo y ornamento: Trazas y dibujos de artes decorativas entre Portugal, España e Italia (ss.XVI-XVIII), Roma-Córdoba: De Luca, pp. 304-311.

Delaforce, Angela (2002): Art and patronage in eighteenth-century Portugal. Cambridge: Cambridge University Press. Delaforce, Angela (2019): The Lost Library of the King of Portugal, Londres: Paul Holberton.

Diez del Corral Corredoira, Pilar (2018): "A Lisbona le spalle, a Roma il volto. Vieira Lusitano un artista portugués en la Roma del Primo Settecento". En: Varela Braga, Ariane / True, Thomas (eds.): Roma e gli artisti stranieri. Intregrazione, reti e identità (ss. XVI-XX), Roma: Pensieri d'Arte, pp. 189-202.

Diez del Corral Corredoira, Pilar (2018b): "Modelo e identidad de la Academia de Francia en Roma: Nicolas Vleughels y su relación con los artistas portugueses y españoles". En: Arte, Individuo y Sociedad 30 (3), pp. 541-555; http:// dx.doi.org/10.5209/ARIS.57966.

Diez del Corral Corredoira, Pilar (2019): "L'Accademia del Portogallo: emulation and strategy in the Papal City". En: Diez del Corral, Pilar (ed.): Politics and the arts in Lisbon and Rome: The Roman dream of John Vof Portugal, Oxford University Studies in the Enlightenment, Liverpool: Liverpool University Press, pp. 93-122.

Diez del Corral Corredoira, Pilar (2021): "Felicitas Duplex: A Vieira Lusitano's medal celebrating the Hispano-Portuguese double-wedding of 1729”. En: Diez del Corral, Pilar (ed.): Fluctuating Alliances. Art, politics and diplomacy in the Modern Era (16-18th centuries), Berlín-Boston: De Gruyter, pp. 43-54.

Diez del Corral, Pilar / Fernandes, Cristina (2020): "Del Tajo al Tíber: la formación de músicos y artistas portugueses en Roma durante el reinado de Juan V (1707-1750)". En: Revista de Historia Moderna. Anales de la Universidad de Alicante 38, pp. 326-359. https://doi.org/10.14198/RHM2020.38.10

Fernandes, Cristina (2021): "Eventi-spettacolo nella cerchia di André de Melo e Castro, ambasciatore portoghese a Roma (1718-1728): aspetti materiali, sociali e politici della performance”. En: Domínguez, Jose María / Elodie Oriol / Anne-Maddeleine Goulet, (eds.): Spectacles et performances artistiques à Rome (1644-1740). Une analyse historique à partir des archives familiales, Roma: École Française de Rome, pp. 353-375.

Lamas, Arthur (1907): "Medalha commemorativa da institução da Academia Real da Historia Portuguesa". En: $O$ Arqueólogo portugués 12 , pp. 52-70.

Lefort, Paul (1869): Catalogue de la Collection de Dessins Anciens des Maitres Espagnols, Flamands, Franrais, Hollandais et Italiens. Composant le Cabinet de M. Paul Lefort, París.

Martín Marcos, David (2019): "Beyond policy: shaping the image of John V of Portugal in Rome". En: Diez del Corral,

${ }^{45}$ BNP, E.75 PQ. : <http://purl.pt/22541> [08/01/2021]. 
Pilar (ed.): Politics and the arts in Lisbon and Rome: The Roman dream of John V of Portugal, Oxford University Studies in the Enlightenment, Liverpool: Liverpool University Press, pp. 17-41.

Megow, Wolf-Rüdiger (1987): Kameen von Augustus bis Alexander Severus, Berlin: De Gruyter.

Mínguez Cornelles, Víctor (2001): Los Reyes Solares: iconografia astral de la monarquía hispánica, Castellón: Publicaciones Universitat Jaume I.

Moreira das Neves, Pe. (1940): "Nossa Senhora da Conceição na Restauração de Portugal”. En: Revista dos Centenários 19-20, pp. 2-8.

Pereira, Ana Cristina Duarte (2008): "Troca das Princesas Maria Bárbara de Bragança e Maria Ana Vitória: O reatar das boas relações ibéricas?”. En: Martínez Millán, José / Marçal Lourenço, Maria Paula (eds.), Las Relaciones Discretas entre las Monarquías Hispana y Portuguesa: las Casas de las Reina (Siglos XV-XIX), Madrid: Polifemo, pp. 567577.

Pernas, Carlos Andrade (2018): “As medalhas dos Mengin”. En: Revista Moeda XLIII-3, pp. 201-207.

Pimentel, Antonio Filipe (2010): "El 'intercambio de las princesas': arte y política en las fiestas de la boda entre Fernando de Borbón y Bárbara de Braganza". En: Quintana 9, pp. 49-73.

Ribeiro, Marília de Azambuja (2019): "Politics, Spectacle and Propaganda: the political Use of Patronage and Press by John V's Representatives in Rome during the first half of the 18th Century". En: Diez del Corral, Pilar (ed.): Politics and the arts in Lisbon and Rome: The Roman dream of John Vof Portugal, Oxford University Studies in the Enlightenment, Liverpool: Liverpool University Press, pp. 43-74.

Schreiner, Klaus (2001): “'Gerechtigkeit und Frieden haben sich geküsst' (Ps 84, 11). Friedensstiftung durch symbolisches Handeln”. En: Meier, Ulrich/ Schwerhoff, Gerd / Signori, Gabriela (eds.), Rituale, Zeichen, Bilder. Formen und Funktionen symbolischer Kommunikation im Mittelalter, Colonia: Böhlau, pp. 65-124.

Seigneur, Marie-Christine (2004): “On Counterproofs”. En: Print Quarterly, 21(2), pp. 115-127.

Turner, Nicholas (2007): "New light on Vieira Lusitano as a draftsman". En: Master Drawings 45 (3), pp. 367-386.

Vieira Lusitano, F. (1780): O Insigne y leal Esposo, Vieira Lusitano, Histórica Verdadeira, que elle escreve em Cantos Lyricos, E ofrece ao Illust. E Excellent. Senhor José da Cunha Grande Ataide e Mello, Conde e Senhor de Povolide, do Conselho de Sua Magestade Fidelissima, Gentil-homm da Sua Real Camara, Comendador da Ordem de Cristom Acaide mór da Vila de Sernancelhe, \&c., Lisboa: Oficina Patriarcal de Francisco Luiz Ameno.

Wohlfeil, Rainer (1991): "Pax antwerpiensis. Eine Fallstudie zu Verbildlichungen der Friedensidee im 16. Jahrhundert am Beispiel der Allegorie 'Kuß von Gerechtigkeit und Friede'”. En: Tolkemitt, Brigitte (ed.): Historische Bildkunde. Probleme, Wege, Beispiele, Berlín: Duncker und Humblot, pp. 211-260.

Fecha de recepción: 11-III-2021

Fecha de aceptación: 06-VIII-2021 